\title{
Uterine Artery Doppler in Screening for Preeclampsia and Fetal Growth Restriction
}

\section{Doppler das artérias uterinas no rastreamento para pré-eclâmpsia e restrição do crescimento fetal}

\author{
Marianna Amaral Pedroso ${ }^{1}$ Kirsten Rebecca Palmer ${ }^{2}$ Ryan James Hodges ${ }^{2}$ Fabricio da Silva Costa ${ }^{2}$ \\ Daniel Lorber Rolnik² \\ ${ }^{1}$ Hospital Mater Dei, Belo Horizonte, MG, Brazil \\ 2 Department of Obstetrics and Gynecology, Monash University, \\ Melbourne, Australia \\ Address for correspondence Daniel Lorber Rolnik, MD, Perinatal \\ Services, Monash Medical Centre, Melbourne, 246, Clayton Road, \\ Clayton, VIC 3168, Australia (e-mail: daniel.rolnik@nhs.net).
}

Rev Bras Ginecol Obstet 2018;40:287-293.

\begin{abstract}
Keywords

- screening

- preeclampsia

- fetal growth restriction

- uterine arteries

- doppler
\end{abstract}

\section{Resumo}

Objective To perform a comprehensive review of the current evidence on the role of uterine artery Doppler, isolated or in combination with other markers, in screening for preeclampsia (PE) and fetal growth restriction (FGR) in the general population. The review included recently published large cohort studies and randomized trials.

Methods A search of the literature was conducted using Medline, PubMed, MeSH and ScienceDirect. Combinations of the search terms "preeclampsia," "screening," "prediction," "Doppler," "Doppler velocimetry," "fetal growth restriction," "small for gestational age" and "uterine artery" were used. Articles in English (excluding reviews) reporting the use of uterine artery Doppler in screening for PE and FGR were included. Results Thirty articles were included. As a single predictor, uterine artery Doppler detects less than $50 \%$ of the cases of PE and no more than $40 \%$ of the pregnancies affected by FGR. Logistic regression-based models that allow calculation of individual risk based on the combination of multiple markers, in turn, is able to detect $\sim 75 \%$ of the cases of preterm PE and $55 \%$ of the pregnancies resulting in small for gestational age infants.

Conclusion The use of uterine artery Doppler as a single predictive test for PE and FGR has poor accuracy. However, its combined use in predictive models is promising, being more accurate in detecting preterm PE than FGR.

Objetivo Realizar revisão da literatura científica acerca do uso do Doppler das artérias uterinas, de forma isolada ou em combinação com outros marcadores, no rastreamento para pré-eclâmpsia (PE) e restrição do crescimento fetal (RCF) na população geral. A revisão incluiu estudos de coorte e ensaios clínicos randomizados recentemente publicados.

Métodos Realizou-se uma pesquisa da literatura nas bases de dados Medline, PubMed, MeSH e ScienceDirect. Diferentes combinações dos termos "preeclampsia," received

December 7, 2017

accepted

March 3, 2018
DOI https://doi.org/

10.1055/s-0038-1660777. ISSN $0100-7203$.
Copyright $\odot 2018$ by Thieme Revinter

Publicações Ltda, Rio de Janeiro, Brazil
License terms

(ㄷ) (i) $\ominus$ (5) 
"screening," “prediction," “Doppler," “Doppler velocimetry," "fetal growth restriction," "small for gestational age" e "uterine artery" foram utilizadas. Artigos em inglês, (excluindo-se artigos de revisão) em que o Doppler das artérias uterinas é reportado como ferramenta no rastreamento para PE e RCF foram incluídos.

Resultados Trinta artigos foram incluídos. Como teste preditivo isolado, o Doppler das artérias uterinas tem sensibilidade inferior a $50 \%$ na detecção de casos de PE e inferior a $40 \%$ para identificação de gestações afetadas por RCF. Modelos matemáticos preditivos baseados em equações de regressão logística que permitem o cálculo de risco individual, por sua vez, são mais promissores, permitindo a detecção de $75 \%$ dos casos de PE pré-termo, e $55 \%$ das gestações que resultarão em parto de recém-nascidos pequenos para a idade gestacional.

Conclusão O uso do Doppler das artérias uterinas tem baixa acurácia na identificação de gestações afetadas por PE e RCF. No entanto, seu uso combinado com outros marcadores é mais promissor, apresentando maior acurácia para detecção de PE do que para RCF.

\section{Introduction}

Preeclampsia (PE) constitutes an important cause of maternal and perinatal morbidity and mortality both in low- and high-income countries, accounting for one in five maternal deaths and $\sim 15 \%$ of all premature deliveries. ${ }^{1}$ It is estimated that one maternal death occurs every 12 minutes due to PE and its complications. Moreover, there is consistent evidence showing that women who had PE in their pregnancies have a significantly increased rate of cardiovascular disease in the future. Compared with women that had uncomplicated pregnancies, women affected by PE have a four-fold increased risk of heart failure and a twofold increased risk of stroke and death from cardiovascular causes. The severity and the gestational age of onset of PE appear to further influence the rate of long-term cardiovascular morbidity. ${ }^{2}$

The financial burden of PE is also enormous, estimated at US\$ 6.4 billion per year in the United States of America, with an average cost of more than US\$ 40,000 per affected pregnancy. $^{3}$

Similarly, fetal growth restriction (FGR), often associated with PE and defined as an estimated fetal weight below the $10^{\text {th }}$ percentile as a consequence of impaired placentation (identified by ultrasound as abnormal uterine arteries or umbilical artery Doppler studies) or estimated fetal weight below the $3^{\text {rd }}$ percentile even with normal Doppler studies, ${ }^{4,5}$ is an important cause of perinatal morbidity and mortality. It is associated with higher rates of antepartum and intrapartum fetal distress, as well as neurodevelopmental, metabolic and cardiovascular diseases in late infancy and adulthood. ${ }^{6,7}$ Approximately a quarter of all stillbirths are associated with $\mathrm{FGR},{ }^{8}$ with many often undetected as being FGR antenatally. Currently, differentiating the constitutionally small fetus from those affected by placental insufficiency remains a clinical challenge.

The use of maternal risk factors (such as maternal age, BMI, previous pregnancy affected by PE or FGR, smoking) and of the symphyseal-fundal height measurement are clearly not accurate enough in the prediction of PE and FGR with detection rates of, at most, of 20 to $40 \%{ }^{9}$

Although the exact mechanism of placental-related disorders is yet to be understood, it is believed that inadequate trophoblastic invasion is implicated in these cases. ${ }^{10-12}$ Impaired development of the placenta translates into persistently elevated resistance to blood flow in the uteroplacental circulation. This is reflected in abnormal waveform patterns of the uterine arteries on sonographic Doppler velocimetry evaluation, with increased pulsatility and resistance indices seen. ${ }^{13,14}$ Therefore, this method of hemodynamic evaluation could possibly be used as a screening test to identify pregnancies at increased risk of PE and FGR. ${ }^{14}$

Additionally, alterations in the concentrations of a range of proteins within the maternal circulation, such as pregnancy associated plasma protein-A (PAPP-A), placental growth factor (PIGF), ${ }^{15,16}$ and soluble fms-like tyrosine kinase-1 (sFlt-1), ${ }^{17-19}$ are often seen in women who go on to develop PE and FGR. These biomarkers provide the potential for use as predictive markers, particularly in cases of early-onset disease. ${ }^{16,18-20}$

In general, the performance of these tests is poor when used as a standalone screening method, and the prediction of late-onset ( $>34$ weeks of gestation) or term PE and FGR is poor, highlighting the possibility that the mechanism of disease may be related to underlying maternal cardiovascular and endothelial dysfunction rather than primary placental insufficiency. ${ }^{21}$

One of the biggest challenges of modern obstetrics is to identify high-risk women as early as possible. This requires effective screening tools to enable the implementation of preventive measures that could possibly reduce the risk of PE and FGR, as well as their consequences. ${ }^{22,23}$ There is a clear trend in the literature over the past 30 years toward attempting to predict pregnancy complications in the first trimester, a concept known as "inversion of the pyramid of prenatal care." 23 Furthermore, apart from the fact that high-risk 
women can be monitored closely looking for signs of PE or fetal growth deviations, recent randomized trials and metaanalyses have shown that prevention is now possible through the use of low-dose aspirin, which when initiated before 16 weeks of gestation significantly reduces the risk of severe $\mathrm{PE}^{24,25}$ that would otherwise require premature delivery. The effect on a possible reduction of the prevalence of FGR was demonstrated in a previous meta-analysis, ${ }^{24}$ but could not be confirmed in a recent large randomized trial (the study was underpowered for this secondary outcome). ${ }^{25}$

The aim of this article is to review the current literature regarding the role of uterine artery Doppler in screening for PE and FGR.

\section{Methods}

A literature search was conducted using Medline, PubMed, $\mathrm{MeSH}$ and ScienceDirect. Combinations of the search terms "preeclampsia," “screening," “prediction,” “Doppler,” “Doppler velocimetry," "fetal growth restriction," "small for gestational age" and "uterine artery" were used, and abstracts were reviewed to identify articles of interest. Peer-reviewed articles published in English and related to the use of uterine artery Doppler isolated or in association with other markers in screening for placental-related disorders (PE and FGR) were included. Reviews and articles in languages other than English were excluded.

\section{Results}

The primary search returned 97 articles. Of those, 30 met the inclusion criteria and were included in this review.

\section{Uterine Artery Doppler Velocimetry}

1. Physiologic changes of the uteroplacental circulation in pregnancy

In 1983, Campbell et al ${ }^{13}$ described a novel technique for evaluation of the vascular resistance in the uterine arteries using pulsed Doppler. In normal pregnancies, a decrease in the uterine artery vascular resistance in the second trimester has also been described. This denotes a significant pattern modification in relation to the one presented by women that are non-pregnant or in the first trimester of pregnancy (-Fig. 1), which possibly reflects the second wave of trophoblastic invasion of spiral arteries that is completed between 16 and 18 weeks of gestation. ${ }^{26}$

In pregnancies complicated by PE and/or FGR, frequently a decrease in resistance does not happen, leading to significantly increased peak systolic velocity, resistance and pulsatility indices (RI and PI, respectively). ${ }^{27}$ It is hypothesized that the mechanism of disease in late-onset PE and FGR is different, with no clear evidence of defective placentation, suggesting that in these cases the maternal cardiovascular system may be involved, and that the clinical manifestations may be due to the placenta no longer being able to meet the oxygen and nutrients demands of the fetus at its greatest. ${ }^{28}$

2. Technical aspects

The ultrasound evaluation of the uterine arteries with Doppler should be performed following a standardized technique to obtain consistent and accurate measurements. It can be done both by abdominal and transvaginal ultrasound. In the first trimester ( 11 to $13^{+6}$ weeks' gestation), a sagittal view of the cervix should be obtained with identification of the cervical canal and the internal cervical os. Subsequently, the ultrasound transducer is slightly angulated laterally with the color Doppler applied, enabling both uterine arteries to be identified at the level of the internal os (- Fig. 1A). ${ }^{29}$

In the second and third trimesters, a similar technique is adopted, but the uterine arteries should be identified at the level where they cross the external iliac artery, since the visualization of the cervical internal os is more difficult with advancing gestational age (-Fig. 1B).$^{30}$ Pulsed wave Doppler is then applied with a sampling volume of $2 \mathrm{~mm}$ and insonation angle $<30^{\circ} .{ }^{29}$ The acquisition of at least three similar waves is recommended and, after correction of the insonation angle, the peak systolic velocity should be higher than $60 \mathrm{~cm} / \mathrm{s}$, ensuring that the insonated vessel is the uterine artery in its proximal portion. The mean uterine artery pulsatility index (PI) is then obtained using the average PI measurement of both right and left arteries. Measurements done in distal segments of the vessel tend to have a lower PI, whereas cervical branches overestimate the risk of pregnancy complications as they have higher PI values. $^{31}$

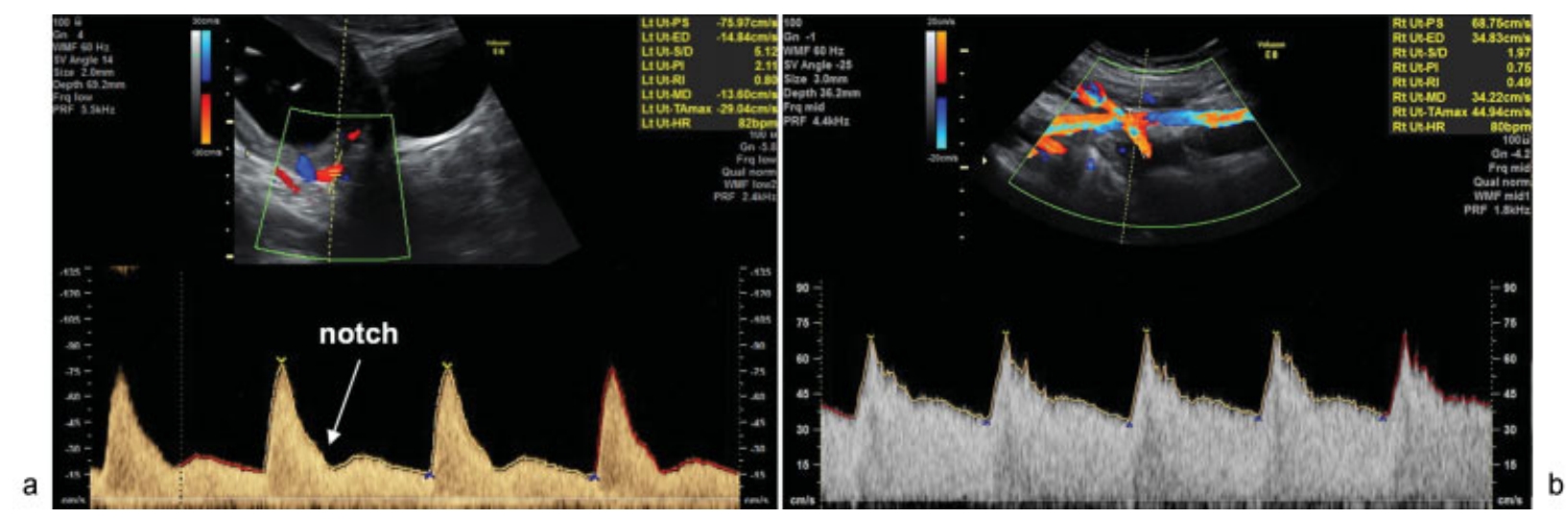

Fig. 1 Doppler velocimetry of the uterine arteries showing a high resistance pattern with notching between the systolic and the diastolic components of the wave (A), characteristic of the first trimester, and a low resistance pattern (B), characteristic of the second trimester. 
Transvaginal measurements are performed in a similar manner, positioning the transducer in the anterior vaginal fornix. $^{27,29}$ This technique, however, leads to higher PI values, ${ }^{32}$ and therefore transabdominal ultrasound is preferred.

3. Uterine artery Doppler as a single predictor of PE and FGR

In the 1990s and early 2000s, various studies reported a clear association between high resistance to blood flow in the uterine arteries and an increased risk of pregnancy complications, ${ }^{14,33-35}$ and reference ranges have been previously established. ${ }^{36}$ Nevertheless, the positive predictive value and the sensitivity of the test were poor in predicting adverse pregnancy outcomes. ${ }^{14}$

Lees et $\mathrm{al}^{34}$ demonstrated that the mean uterine artery PI above the $95^{\text {th }}$ percentile, measured at 23 weeks of gestation, has a strong association with poor fetal growth, placental abruption, PE and fetal death. Its use as a screening test would possibly allow for individual risk assessment and selection of patients who require close monitoring and an adequate delivery plan. ${ }^{34}$ In the same year, Papageorghiou et $\mathrm{al}^{37}$ reported that mean uterine artery PI above the $95^{\text {th }}$ percentile (1.63) in the second trimester detected only $41 \%$ of the cases of PE and 16\% of those complicated by FGR. Despite the low sensitivity, the same cutoff was able to detect $93 \%$ of the PE cases and 56\% of the FGR cases that required delivery before 32 weeks of gestation. ${ }^{37}$ Yu et al ${ }^{14}$ evaluated more than 30,000 pregnancies in 2008, and, similarly, found that uterine artery Doppler was able to predict most cases of preterm PE, but not the ones that happened at term. ${ }^{14}$

Using the $95^{\text {th }}$ percentile as a unique cutoff value ( 2.35 at 11 to $13^{+6}$ weeks $^{38}$ and 1.60 at 18 to 24 weeks) does not seem to be appropriate, as different maternal characteristics, such as ethnic origin, weight and height, independently influence the PI values. Hence, the utilization of a unique value might not accurately reflect the resistance levels, and the expression of the mean PI in multiples of the median (MoM) after adjustment for maternal characteristics is preferable. ${ }^{39}$

In a recent meta-analysis including 18 studies and more than 55,000 pregnancies, the use of uterine arteries PI above the $90^{\text {th }}$ percentile in the first trimester was only able to identify $47 \%$ of the cases of early-onset PE and $39.2 \%$ of the cases of early-onset FGR, with a false-positive rate of $7 \% .{ }^{40}$ The identification of presence or absence of diastolic notching as a marker of vascular resistance (-Fig. 1A) also has low sensitivity and specificity, mainly in the first trimester, when it is present in more than half of the cases. ${ }^{40}$

In twin pregnancies, the uterine artery Doppler for prediction of pregnancy adverse outcomes has been less studied. The mean PI tends to be lower and even less predictive of complications secondary to placental dysfunction. ${ }^{41}$

In summary, although the mean uterine artery PI evaluated by Doppler is significantly elevated in patients who will develop early and severe forms of PE or FGR, the accuracy of this test as a standalone screening tool is poor, with low sensitivity and positive predictive value. Its use as part of predictive algorithms that combine maternal characteristics, maternal history and other biophysical and biochemical markers seems more promising, ${ }^{42}$ with higher detection rates and acceptable false-positive rates. ${ }^{43}$

\section{Multimarker Screening and Predictive Algorithms}

Traditional methods of stratification of risk for PE and FGR are based on a detailed evaluation of maternal characteristics and medical history. Two commonly used methods are in the guidelines from the National Institute for Health and Care Excellence (NICE), from the United Kingdom (UK), ${ }^{44}$ and the American College of Obstetricians and Gynecologists (ACOG), in the United States of America (USA). ${ }^{45}$

In the UK, the national policy is to apply the protocol recommended by the NICE guidelines in the first prenatal visit, with pregnant women considered high-risk for PE if they have one high risk factor (history of hypertensive disease in previous pregnancy, chronic kidney disease, autoimmune disease (not specified in the guidelines), diabetes mellitus or chronic hypertension) or two moderate-risk factors (first pregnancy, age $>40$ years, interpregnancy interval $>10$ years, body mass index [BMI] at first visit $>35 \mathrm{~kg} / \mathrm{m} 2$ or family history of PE). ${ }^{44}$

Likewise, the ACOG recommendations suggest that a pregnant woman is high-risk for PE if she has any of the following risk factors: nulliparity, age $>40$ years, body mass index $>30 \mathrm{~kg} / \mathrm{m} 2$, conception by in vitro fertilization (IVF), history of previous pregnancy with PE, family history of systemic lupus erythematosus or thrombophilia. ${ }^{45}$

The main problems with these approaches is that they lack validation with prospective studies and they attribute similar weights to different factors that actually impact differently on one's risk of developing PE. Recent studies suggest that the NICE guidelines identify only $\sim 40 \%$ of the cases of PE that require delivery before 37 weeks of gestation. The ACOG recommendations, in turn, allow detection of $90 \%$ of these cases, but with a very high false-positive rate of $64.2 \%{ }^{43}$

Several studies have been published proposing an alternative approach based on multiple regression predictive models. ${ }^{16,22}$ Such algorithms aim to estimate the individual's pretest (a priori risk) and posttest (adjusted risk) probability of developing PE and FGR based not only on maternal risk factors, but also on a combination of biophysical and biochemical markers. $^{16}$

The most studied and used algorithm for PE risk calculation at the 11 to $13^{+6}$ weeks ultrasound, at the same time of the first trimester combined screening for chromosomal abnormalities, is the one developed by the Fetal Medicine Foundation (FMF). ${ }^{16,42}$ This method uses different combinations of maternal factors with biophysical markers (mean arterial pressure [MAP] and mean uterine artery PI, which are significantly elevated in women that will later develop severe and preterm forms of FGR and PE) and biochemical markers (PAPP-A and PIGF, which are significantly reduced in women that will later develop severe and early forms of PE and FGR) to estimate the risk of PE and FGR (- Table 1). When all markers are used, $\sim 90 \%$ of the PE cases that require delivery before 32 weeks, $75 \%$ of the PE cases that require delivery before 37 weeks and 55\% of the cases of FGR that require delivery before 34 weeks can be identified in the first trimester. ${ }^{16,42}$ Even in low-resource settings where biochemical tests may not be available, the combination of maternal factors with MAP and uterine artery Doppler still detects a large proportion of PE cases (- Table 1). ${ }^{16,46-48}$ 
Table 1 Detection rates and false-positive results for different combinations of markers in the Fetal Medicine Foundation algorithm for preeclampsia

\begin{tabular}{|c|c|c|c|c|c|c|}
\hline \multirow[t]{3}{*}{ Screening method } & \multicolumn{2}{|c|}{$\mathrm{PE}<32$ weeks } & \multicolumn{2}{|c|}{$\mathrm{PE}<37$ weeks } & \multicolumn{2}{|c|}{ PE > 37 weeks } \\
\hline & \multicolumn{2}{|c|}{ Detection rate (\%) } & \multicolumn{2}{|c|}{ Detection rate (\%) } & \multicolumn{2}{|c|}{ Detection rate (\%) } \\
\hline & FP $5 \%$ & FP $10 \%$ & FP $5 \%$ & FP $10 \%$ & FP $5 \%$ & FP $10 \%$ \\
\hline Maternal factors & 41 & 53 & 29 & 41 & 18 & 37 \\
\hline \multicolumn{7}{|l|}{ Maternal factors plus: } \\
\hline MAP & 59 & 71 & 36 & 47 & 26 & 37 \\
\hline UtPI & 71 & 82 & 47 & 61 & 22 & 39 \\
\hline UtPI, MAP & 82 & 94 & 53 & 71 & 27 & 41 \\
\hline UtPI, PAPP-A & 71 & 82 & 49 & 66 & 24 & 40 \\
\hline UtPI, PIGF & 82 & 100 & 61 & 75 & 22 & 39 \\
\hline UtPI, MAP, PAPP-A & 88 & 94 & 61 & 69 & 29 & 42 \\
\hline UtPI, MAP, PIGF & 94 & 100 & 66 & 75 & 32 & 43 \\
\hline UtPI, PAPP-A, PIGF & 82 & 100 & 61 & 75 & 23 & 38 \\
\hline UtPI, MAP, PAPP-A, PIGF & 94 & 100 & 66 & 80 & 31 & 43 \\
\hline
\end{tabular}

Abbreviations: FP, false-positive; MAP, mean arterial pressure; PAPP-A, pregnancy associated plasma protein-A; PE, preeclampsia; PIGF, placental growth factor; UtPI, mean uterine artery pulsatility index.

The risk calculation can be performed with the use of commercial ultrasound software that contains the equations or can be done freely online (www.fetalmedicine.org). ${ }^{16}$ The algorithm has been prospectively validated in different populations, with similar results obtained to those seen during the original development of the model. ${ }^{49-53}$ In the recently published Aspirin for Evidence-based Preeclampsia Prevention (ASPRE) trial, 26,941 women were screened for preterm $\mathrm{PE}$ in the first trimester with the FMF algorithm, and $76 \%$ of the cases were detected at a cutoff of $1: 100 .^{52}$ Early initiation of $150 \mathrm{mg}$ of aspirin at 12 weeks of gestation reduced the incidence of preterm PE by $62 \%$ and of PE requiring delivery before 34 weeks by $82 \%$. Moreover, the incidence of FGR in the randomized population was twice as high as would be expected in the general population, highlighting the similar placental origin of both conditions. ${ }^{25}$ Although the study was not powered for the reduction of FGR and this was not significant, there was a trend for reduction of stillbirths, neonatal deaths and FGR among those receiving aspirin. ${ }^{25}$

Similar risk calculations can be performed in the second and third trimesters. ${ }^{17,47}$ No preventive interventions were proven to reduce the incidence of PE or FGR when started after 16 weeks of gestation, but in many countries, a significant number of women start prenatal care after 16 weeks of gestation ${ }^{54}$ and identifying high-risk patients could still be of value in offering them close monitoring of blood pressure and fetal growth surveillance. ${ }^{55}$

Multimarker approaches could theoretically be applied in twin pregnancies, but the false-positive rate seems to be much higher (around 75\%). Furthermore, there is insufficient data as to whether preventive measures that are proven to work in singleton pregnancies, such as low-dose aspirin started before 16 weeks of gestation, will also work in multiple pregnancies. ${ }^{56}$
While first trimester predictive algorithms for PE appear to be promising, the same approach for FGR detects only half of the cases that will require premature delivery. ${ }^{42}$ The identification of women that should be offered third trimester serial fetal growth assessment by ultrasound remains based on the identification of maternal risk factors, such as maternal health conditions, obstetric history of a previous pregnancy affected by FGR and smoking status.

For the prediction of late-onset PE and FGR (at term), none of the methods described has satisfactory accuracy. This highlights the possibility that these cases are more related to underlying maternal cardiovascular dysfunction or placental insufficiency at term rather than inadequate trophoblastic invasion, since most biomarkers predictive of inadequate placental development perform poorly for term PE and FGR. Equally, prevention with aspirin does not seem to reduce the incidence of PE and FGR at term. ${ }^{25,54,57}$

\section{Conclusion}

Prediction of PE and FGR remains an important challenge in clinical practice. Screening by maternal characteristics and history has poor sensitivity, as well as the utilization of uterine artery Doppler or any other marker alone. There is a clear association of elevated mean uterine artery PI, in both first and second trimesters, with the occurrence of PE and FGR, but its application as an isolated screening test shows low positive predictive value and sensitivity. The combination of uterine artery Doppler, maternal risk factors and mean arterial pressure, with or without circulating biomarkers, increases the detection rate (sensitivity) and reduces false-positive results in identifying the high-risk group that benefits from aspirin use and those most at risk of a premature delivery, which are largely responsible for most of the 
morbidity, mortality and economic burden related to placental disease.

\section{Conflicts of Interest}

The authors report no conflicts of interest.

\section{References}

1 Duley L. The global impact of pre-eclampsia and eclampsia. Semin Perinatol 2009;33(03):130-137. Doi: 10.1053/j.semperi.2009.02.010

2 Wu P, Haththotuwa R, Kwok CS, et al. Preeclampsia and future cardiovascular health: a systematic review and meta-analysis. Circ Cardiovasc Qual Outcomes 2017;10(02):e003497. Doi: 10.1161/CIRCOUTCOMES.116.003497

3 Stevens W, Shih T, Incerti D, et al. Short-term costs of preeclampsia to the United States health care system. Am J Obstet Gynecol 2017;217(03):237-248.e16

4 Figueras F, Gratacos E. An integrated approach to fetal growth restriction. Best Pract Res Clin Obstet Gynaecol 2017;38:48-58. Doi: 10.1016/j.bpobgyn.2016.10.006

5 Gordijn SJ, Beune IM, Thilaganathan B, et al. Consensus definition of fetal growth restriction: a Delphi procedure. Ultrasound Obstet Gynecol 2016;48(03):333-339. Doi: 10.1002/uog.15884

6 Roseboom TJ, van der Meulen JH, Osmond C, et al. Coronary heart disease after prenatal exposure to the Dutch famine, 1944-45. Heart 2000;84(06):595-598. Doi: 10.1136/heart.84.6.595

7 Roseboom TJ, van der Meulen JH, Ravelli AC, Osmond C, Barker DJ, Bleker OP. Effects of prenatal exposure to the Dutch famine on adult disease in later life: an overview. Twin Res 2001;4(05): 293-298. Doi: 10.1375/1369052012605

8 Flenady V, Koopmans L, Middleton P, et al. Major risk factors for stillbirth in high-income countries: a systematic review and metaanalysis. Lancet 2011;377(9774):1331-1340. Doi: 10.1016/S01406736(10)62233-7

9 Sovio U, White IR, Dacey A, Pasupathy D, Smith GCS. Screening for fetal growth restriction with universal third trimester ultrasonography in nulliparous women in the Pregnancy Outcome Prediction (POP) study: a prospective cohort study. Lancet 2015;386 (10008):2089-2097. Doi: 10.1016/S0140-6736(15)00131-2

10 Brosens IA, Robertson WB, Dixon HG. The role of the spiral arteries in the pathogenesis of preeclampsia. Obstet Gynecol Annu 1972;1:177-191

11 Wallace AE, Fraser R, Gurung S, et al. Increased angiogenic factor secretion by decidual natural killer cells from pregnancies with high uterine artery resistance alters trophoblast function. Hum Reprod 2014;29(04):652-660. Doi: 10.1093/humrep/deu017

12 Wallace AE, Whitley GS, Thilaganathan B, Cartwright JE. Decidual natural killer cell receptor expression is altered in pregnancies with impaired vascular remodeling and a higher risk of preeclampsia. J Leukoc Biol 2015;97(01):79-86. Doi: 10.1189/ jlb.2A0614-282R

13 Campbell S, Diaz-Recasens J, Griffin DR, et al. New doppler technique for assessing uteroplacental blood flow. Lancet 1983; 1(8326 Pt 1):675-677. Doi: 10.1016/S0140-6736(83)92546-1

14 Yu CK, Khouri O, Onwudiwe N, Spiliopoulos Y, Nicolaides KH; Fetal Medicine Foundation Second-Trimester Screening Group. Prediction of pre-eclampsia by uterine artery Doppler imaging: relationship to gestational age at delivery and small-for-gestational age. Ultrasound Obstet Gynecol 2008;31(03):310-313. Doi: 10.1002/uog.5252

15 Mundim GJ, Paschoini MC, Araujo Júnior E, Da Silva Costa F, Rodrigues Júnior V. Assessment of angiogenesis modulators in pregnant women with pre-eclampsia: a case-control study. Arch Gynecol Obstet 2016;293(02):369-375. Doi: 10.1007/s00404015-3823-X
16 O'Gorman N, Wright D, Syngelaki A, et al. Competing risks model in screening for preeclampsia by maternal factors and biomarkers at 11-13 weeks gestation. Am J Obstet Gynecol 2016;214(01):103. e1-103.e12

17 Gallo DM, Wright D, Casanova C, Campanero M, Nicolaides KH. Competing risks model in screening for preeclampsia by maternal factors and biomarkers at 19-24 weeks' gestation. Am J Obstet Gynecol 2016;214(05):619.e1-619.e17. Doi: 10.1016/j.ajog.2015.11.016

18 Palmer KR, Kaitu'u-Lino TJ, Cannon P, et al. Maternal plasma concentrations of the placental specific sFLT-1 variant, sFLT-1 e15a, in fetal growth restriction and preeclampsia. J Matern Fetal Neonatal Med 2017;30(06):635-639. Doi: 10.1080/14767058.2016.1182975

19 Palmer KR, Kaitu'u-Lino TJ, Hastie R, et al. Placental-specific sFLT1 e15a protein is increased in preeclampsia, antagonizes vascular endothelial growth factor signaling, and has antiangiogenic activity. Hypertension 2015;66(06):1251-1259. Doi: 10.1161/HYPERTENS IONAHA.115.05883

20 Zeisler H, Llurba E, Chantraine F, et al. Predictive value of the sFlt$1:$ PlGF ratio in women with suspected preeclampsia. N Engl J Med 2016;374(01):13-22. Doi: 10.1056/NEJMoa1414838

21 Verlohren S, Melchiorre K, Khalil A, Thilaganathan B. Uterine artery Doppler, birth weight and timing of onset of pre-eclampsia: providing insights into the dual etiology of late-onset preeclampsia. Ultrasound Obstet Gynecol 2014;44(03):293-298. Doi: 10.1002/uog.13310

22 Gabbay-Benziv R, Oliveira N, Baschat AA. Optimal first trimester preeclampsia prediction: a comparison of multimarker algorithm, risk profiles and their sequential application. Prenat Diagn 2016;36(01):34-39. Doi: 10.1002/pd.4707

23 Nicolaides KH. Turning the pyramid of prenatal care. Fetal Diagn Ther 2011;29(03):183-196. Doi: 10.1159/000324320

24 Roberge S, Sibai B, McCaw-Binns A, Bujold E. Low-dose aspirin in early gestation for prevention of preeclampsia and small-for-gestational-age neonates: meta-analysis of large randomized trials. Am J Perinatol 2016;33(08):781-785. Doi: 10.1055/s-0036-1572495

25 Rolnik DL, Wright D, Poon LC, et al. Aspirin versus placebo in pregnancies at high risk for preterm preeclampsia. N Engl J Med 2017;377(07):613-622. Doi: 10.1056/NEJMoa1704559

26 Wallace AE, Host AJ, Whitley GS, Cartwright JE. Decidual natural killer cell interactions with trophoblasts are impaired in pregnancies at increased risk of preeclampsia. Am J Pathol 2013;183 (06):1853-1861. Doi: 10.1016/j.ajpath.2013.08.023

27 Plasencia W, Maiz N, Poon L, Yu C, Nicolaides KH. Uterine artery Doppler at $11+0$ to $13+6$ weeks and $21+0$ to $24+6$ weeks in the prediction of pre-eclampsia. Ultrasound Obstet Gynecol 2008; 32(02):138-146. Doi: 10.1002/uog.5402

28 Zhang S, Regnault TR, Barker PL, et al. Placental adaptations in growth restriction. Nutrients 2015;7(01):360-389. Doi: 10.3390/ nu7010360

29 Plasencia W, Maiz N, Bonino S, Kaihura C, Nicolaides KH. Uterine artery Doppler at $11+0$ to $13+6$ weeks in the prediction of preeclampsia. Ultrasound Obstet Gynecol 2007;30(05):742-749. Doi: $10.1002 /$ uog.5157

30 Khong SL, Kane SC, Brennecke SP, da Silva Costa F. First-trimester uterine artery Doppler analysis in the prediction of later pregnancy complications. Dis Markers 2015;2015:679730

31 Ridding G, Schluter PJ, Hyett JA, McLennan AC. Influence of sampling site on uterine artery Doppler indices at $11-13^{+6}$ weeks gestation. Fetal Diagn Ther 2015;37(04):310-315. Doi: 10.1159/000366060

32 Plasencia W, Barber MA, Alvarez EE, Segura J, Valle L, GarciaHernandez JA. Comparative study of transabdominal and transvaginal uterine artery Doppler pulsatility indices at $11-13+6$ weeks. Hypertens Pregnancy 2011;30(04):414-420. Doi: 10.3109/106419 55.2010.506232

33 Bower S, Vyas S, Campbell S, Nicolaides KH. Color Doppler imaging of the uterine artery in pregnancy. Ultrasound Obstet Gynecol 1992; 2(05):375. Doi: 10.1046/j.1469-0705.1992.02050375.x 
34 Lees C, Parra M, Missfelder-Lobos H, Morgans A, Fletcher O, Nicolaides $\mathrm{KH}$. Individualized risk assessment for adverse pregnancy outcome by uterine artery Doppler at 23 weeks. Obstet Gynecol 2001;98(03):369-373. Doi: 10.1016/S0029-7844(01)01474-0

35 Bower S, Vyas S, Campbell S, Nicolaides KH. Color Doppler imaging of the uterine artery in pregnancy: normal ranges of impedance to blood flow, mean velocity and volume of flow. Ultrasound Obstet Gynecol 1992;2(04):261-265. Doi: 10.1046/ j.1469-0705.1992.02040261.x

36 Alves JA, Silva BY, de Sousa PC, Maia SB, Costa FdaS. Reference range of uterine artery Doppler parameters between the 11th and 14th pregnancy weeks in a population sample from Northeast Brazil. Rev Bras Ginecol Obstet 2013;35(08):357-362. Doi: 10.1590/S0100-72032013000800004

37 Papageorghiou AT, Yu CK, Bindra R, Pandis G, Nicolaides KH; Fetal Medicine Foundation Second Trimester Screening Group. Multicenter screening for pre-eclampsia and fetal growth restriction by transvaginal uterine artery Doppler at 23 weeks of gestation. Ultrasound Obstet Gynecol 2001;18(05):441-449. Doi: 10.1046/ j.0960-7692.2001.00572.x

38 Martin AM, Bindra R, Curcio P, Cicero S, Nicolaides KH. Screening for pre-eclampsia and fetal growth restriction by uterine artery Doppler at 11-14 weeks of gestation. Ultrasound Obstet Gynecol 2001;18(06):583-586. Doi: 10.1046/j.0960-7692.2001.00594.x

39 Poon LC, Nicolaides KH. Early prediction of preeclampsia. Obstet Gynecol Int 2014;2014:297397

40 Velauthar L, Plana MN, Kalidindi M, et al. First-trimester uterine artery Doppler and adverse pregnancy outcome: a meta-analysis involving 55,974 women. Ultrasound Obstet Gynecol 2014;43 (05):500-507. Doi: 10.1002/uog.13275

41 Svirsky R, Yagel S, Ben-Ami I, Cuckle H, Klug E, Maymon R. First trimester markers of preeclampsia in twins: maternal mean arterial pressure and uterine artery Doppler pulsatility index. Prenat Diagn 2014;34(10):956-960. Doi: 10.1002/pd.4402

42 Poon LC, Syngelaki A, Akolekar R, Lai J, Nicolaides KH. Combined screening for preeclampsia and small for gestational age at 11-13 weeks. Fetal Diagn Ther 2013;33(01):16-27. Doi: 10.1159/000341712

43 O'Gorman N, Wright D, Poon LC, et al. Multicenter screening for pre-eclampsia by maternal factors and biomarkers at 11-13 weeks' gestation: comparison with NICE guidelines and ACOG recommendations. Ultrasound Obstet Gynecol 2017;49(06): 756-760. Doi: 10.1002/uog.17455

44 Visintin C, Mugglestone MA, Almerie MQ Nherera LM, James D, Walkinshaw S; Guideline Development Group. Management of hypertensive disorders during pregnancy: summary of NICE guidance. BMJ 2010;341:c2207. Doi: 10.1136/bmj.c2207

45 Committee Opinion No. 638: first-trimester risk assessment for early-onset preeclampsia. Obstet Gynecol 2015;126(03):e25-e27. Doi: 10.1097/AOG.0000000000001049

46 Rocha RS, Alves JAG, Maia E Holanda Moura SB, et al. Simple approach based on maternal characteristics and mean arterial pressure for the prediction of preeclampsia in the first trimester of pregnancy. J Perinat Med 2017;45(07):843-849. Doi: 10.1515/ jpm-2016-0418

47 Al-Amin A, Rolnik DL, Black C, et al. Accuracy of second trimester prediction of preterm preeclampsia by three different screening algorithms. Aust N Z J Obstet Gynaecol 2017;58:192-196. Doi: 10.1111/ajo.12689

48 Scandiuzzi RM, Prado CA, Araujo Júnior E, et al. Maternal uterine artery Doppler in the first and second trimesters as screening method for hypertensive disorders and adverse perinatal outcomes in low-risk pregnancies. Obstet Gynecol Sci 2016;59(05): 347-356. Doi: 10.5468/ogs.2016.59.5.347

49 O'Gorman N, Wright D, Poon LC, et al. Accuracy of competing-risks model in screening for pre-eclampsia by maternal factors and biomarkers at 11-13 weeks' gestation. Ultrasound Obstet Gynecol 2017;49(06):751-755. Doi: 10.1002/uog.17399

50 Onwudiwe N, Yu CK, Poon LC, Spiliopoulos I, Nicolaides KH. Prediction of pre-eclampsia by a combination of maternal history, uterine artery Doppler and mean arterial pressure. Ultrasound Obstet Gynecol 2008;32(07):877-883. Doi: 10.1002/uog.6124

51 Park FJ, Leung CH, Poon LC, Williams PF, Rothwell SJ, Hyett JA. Clinical evaluation of a first trimester algorithm predicting the risk of hypertensive disease of pregnancy. Aust N Z J Obstet Gynaecol 2013;53(06):532-539. Doi: 10.1111/ajo.12126

52 Rolnik DL, Wright D, Poon LCY, et al. ASPRE trial: performance of screening for preterm pre-eclampsia. Ultrasound Obstet Gynecol 2017;50(04):492-495. Doi: 10.1002/uog.18816

53 Lobo GAR, Nowak PM, Panigassi AP, et al. Validation of Fetal Medicine Foundation algorithm for prediction of pre-eclampsia in the first trimester in an unselected Brazilian population. J Matern Fetal Neonatal Med 2017;2017:1-7. Doi: 10.1080/ 14767058.2017.1378332

54 Turyasiima M, Tugume R, Openy A, et al. Determinants of first antenatal care visit by pregnant women at community based education, research and service sites in Northern Uganda. East Afr Med J 2014;91(09):317-322

55 García B, Llurba E, Valle L, et al. Do knowledge of uterine artery resistance in the second trimester and targeted surveillance improve maternal and perinatal outcome? UTOPIA study: a randomized controlled trial. Ultrasound Obstet Gynecol 2016; 47(06):680-689. Doi: 10.1002/uog.15873

56 Francisco C, Wright D, Benkő Z, Syngelaki A, Nicolaides KH. Competing-risks model in screening for pre-eclampsia in twin pregnancy according to maternal factors and biomarkers at 11-13 weeks' gestation. Ultrasound Obstet Gynecol 2017;50(05): 589-595. Doi: 10.1002/uog.17531

57 Roberge S, Villa P, Nicolaides K, et al. Early administration of lowdose aspirin for the prevention of preterm and term preeclampsia: a systematic review and meta-analysis. Fetal Diagn Ther 2012;31(03):141-146. Doi: 10.1159/000336662 